\title{
Perancangan dan analisis electric car frame "Melumumet" menggunakan software Autodesk Inventor 2016
}

\author{
Munir Amrulloh ${ }^{1 *}$,Eko Nugroho ${ }^{2}$, Asroni $^{3}$ \\ ${ }^{1}$ Prodi Magister Teknik Mesin, Fakultas Teknik, Universitas Muhammadiyah Metro \\ JI. Ki Hajar Dewantara 15 A Kota Metro, Lampung, Indonesia \\ 2, 3 Jurusan Teknik Mesin, Fakultas Teknik, Universitas Muhammadiyah Metro \\ JI. Ki Hajar Dewantara 15 A Kota Metro, Lampung, Indonesia \\ *Corresponding author: muniramrulloh123@yahoo.com
}

\begin{abstract}
Abstrak
Frame atau rangka merupakan bagian penting dalam sebuah alat transportasi yang menyatukan semua komponen dan guna menahan beban yang bertumpu pada frame tersebut kesalahan dalam perancangan pembebanan akan mengakibatkan ketidak nyamanan saat frame akan diaplikasikan, dan juga akan mengurangi faktor keamanan, kenyamanan pengemudi dan penumpang saat digunakan, perancangan frame yang tepat akan memberikan hasil yang optimal antara tingkat keamanan dan kenyamanan, tujuan perancangan rangka kali ini untuk mengetahui displacement yang terjadi pada pada electric car frame menggunakan software autodesk inventor 2016, mengetahui tegangan minimal dan maximal yang terjadi pada electric car frame menggunakan software autodesk inventor 2016, mengetahui safety factor yang terjadi pada electric car frame menggunakan software autodesk inventor 2016 dengan menggunakan fitur frame analysis, maka dapat diketahui fenomena yang terjadi pada struktur frame mobil listrik yang telah dirancang sebelumnya. Penelitian ini dilakukan dengan beberapa tahap metode pengerjaan yaitu : pemodelan frame dengan software autodesk inventor 2016 dengan cara membuat desain 2D terlebih dahulu, lalu merubahnya kedalam 3D, setelah desain selesai masuklah ketahap simulasi, setelah melakukan simulasi dengan beban $230 \mathrm{~kg}, 280 \mathrm{~kg}$, dan $330 \mathrm{~kg}$ terhadap frame didapat hasil berupa displacement 0,6677 $\mathrm{mm}, 0,7243 \mathrm{~mm}$, dan 0,7809 mm, tegangan maximal 23,28 $\mathrm{MPa}, 25,2 \mathrm{MPa}$, dan 27,12 $\mathrm{MPa}$, tegangan minimal $0,04 \mathrm{MPa}, 0,05 \mathrm{MPa}, 0,06 \mathrm{MPa}$, dan angka keamanan yang diperoleh dari analisa tersebut adalah 10,3; 9,5; dan 8,8. Angka keamanan merupakan salah satu faktor utama apakah frame layak diguanakan atau tidak jika hasil yang didapat pada safety factor yaitu kurang dari 1 maka frame tersebut tidak aman saat akan digunakan.
\end{abstract}

Kata kunci: Autodesk, frame, simulation, displacement, stress.

\section{Pendahuluan}

Frame atau rangka merupakan bagian penting dalam sebuah alat tranportasi yang menyatukan semua komponen seperti body mobil, sistem kemudi, roda dan sebagai komponen utama yang berfungsi untuk menopang semua bebana yang ada pada kendaraan seperti body mobil, battery hingga pengemudi itu sendiri, pembebanan pada rangka merupakan salah hal yang penting dalam perancangan, kesalahan dalam perancangan pembebanan akan mengakibatkan ketidaknyamanan saat rangka akan diaplikasikan, dan juga akan mengurangi faktor keamanan pengemudi dan penumpang saat digunakan, perancangan rangka yang tepat akan memberikan hasil yang optimal antara tingkat keamanan dan ukuran konstruksi. Rangka memiliki bentuk dan ukuran yang kompleks, sehingga apabila dilakukan perancangan secara manual akan memiliki banyak kendala. Autodesk Inventor (For Student) Adalah salah satu produk dari Autodesk Corp, yang diperuntungkan untuk para pelajar. Autodesk Inventor merupakan produk dari CAD setelah AutoCad dan Autodeks Mechanical Dekstop, Autodesk 
Inventor Memiliki beberapa kelebihan yang memudahkan Drafter [1].

Enginer dalam mendesain sebuah komponen serta material yang disediakan menyerupai aslinya, hingga saat ini Autodesk Inventor bersaing langsung dengan Solid Works dan Solid Edge, dimana Solid Works dan Solid Edge juga dapat mendesain sebuah komponen, menggabungkan, membuat simulasi pada setiap komponen yang akan diproduksi, dan juga dapat menganimasikannya.

Dari semua teknologi pendukung kendaraan listrik, baterai merupakan teknologi kunci dalam meningkatkan unjuk kerja kendaraan listrik khususnya dalam jarak tempuh. Dengan kondisi teknologi sekarang ini, spesifikasi baterailah yang akan menentukan apakah kendaraan listrik akan bisa dikembangkan agar memiliki jarak tempuh yang panjang. Riset dan pengembangan teknologi baterai saat ini sudah dan sedang berlangsung untuk menghasilkan baterai yang mampu memenuhi kebutuhan energi kendaraan untuk jarak tempuh 320 hingga 563 mil untuk sekali pengisian [2].

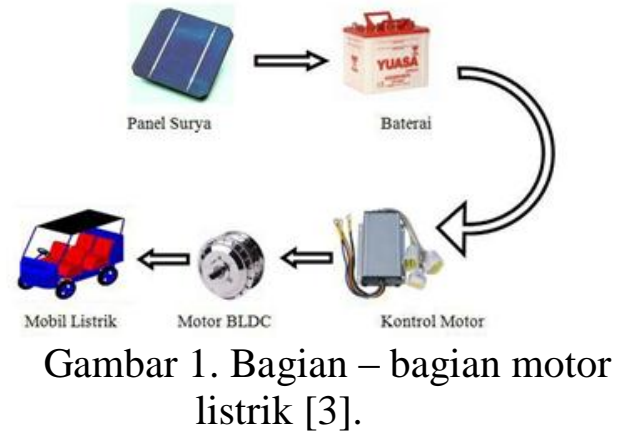

\section{Tinjauan Pustaka}

\section{Mobil Listrik}

Mobil listrik ialah mobil yang digerakan dengan motor listrik, menggunakan energi listrik yang disimpan dalam baterai atau tempat penyimpanan lainnya. Mobil listrik sangat populer pada akhir abad ke-19 dan awal abad ke-20, tapi kemudian popularitas meredup karena teknologi mesin pembakran dalam yang semakin maju dan harga kendaraan berbahan bakar minyak yang semakin murah. Krisis energi pada tahun 1970-an dan 1980-an pernah membangkitkan minat pada mobil listrik, tapi baru pada tahun 2000-an para produsen kendaraan baru menaruh perhatian yang serius pada kendaraan listrik. Hal ini karena disebabkan karena harga minyak yang melambung tinggi pada tahun 2000-an serta banyak masyarakat dunia yang sadar akan dampak buruknya emisi gas rumah kaca [4].

\section{Perancangan dan Analisis}

Perancangan adalah perencanaan dan pembuatan desain atau pengaturan dari beberapa elemen yang terpisah dalam satu kesatuan yang utuh dan berfungsi. Perancangan sistem dapat dirancang dalam bentuk bagan alir sistem (system flowchart), yang merupakan alat bentuk grafik yang dapat digunakan untuk menunjukan urutan-urutan proses dari sistem [5].

Perencanaan suatu produk merupakan bagian yang sangat penting dan sangat menentukan kualitas produk tersebut, perencanaan merupakan kegiatan awal dari rangkaian kegiatan sampai ke proses pembuatan produk sehingga dalam tahap ini juga ditentukan apa yang harus dilakukan dan bagaimana cara melakukannya termasuk merencanakan tahapan pembuatan produk agar mendapatkan kualitas yang diinginkan, apabilah pada tahap perencanaan sudah ditentukan kemudian dilanjutkan ketahap desain.

Sedangkan untuk proses desain itu sendiri adalah langkah dalam suatu fase pengembangan bagi setiap produk atau sistem yang sudah ada maupun yang belum ada. Desain hasil rancangan produk adalah hasil akhir proses perancangan yang nantinya akan menjadi acuan untuk membuat sebuah produk yang diinginkan, gambar rancangan produk berupa gambar teknik yang dibuat pada kertas dua dimensi yang distandarkan atau dalam bentuk modern yang disimpan dalam memori komputer. Secara umum proses perancangan suatu produk melibatkan beberapa proses yang cukup panjang. 


\section{Pengertian Frame atau Rangka Kendaraan}

Frame atau rangka adalah sebuah kontruksi yang berfungsi sebagai penopang beban kendaraan, mesin, serta penumpang. Biasanya rangka dibuat dari besi atau baja, syarat utama yang harus terpenuhi adalah material tersebut harus memiliki kekuatan untuk menopang beban dari kendaraan. Rangka juga berfungsi untuk menjaga agar mobil tetap rigid, kaku, dan tidak mengalami bending atau deformasi saat digunakan nantinya. Rangka adalah suatu struktur yang ujungujungnya disambung kaku, semua batang yang disambung secara kaku dilas, dibaut, atau dikeling mampu menahan gaya aksial, gaya normal, dan momen. Elemen rangka merupakan elemen dua dimensi dan kombinasi antara elemen truss dan beam, sehingga ada tiga macam simpangan pada setiap titik nodal yaitu simpangan horisontal, vertikal, dan rotasi. Oleh karena itu dibutuhkan material yang kuat untuk memenuhi spesifikasi tersebut. Pada umumnya rangka mobil mempunyai kontruksi yang sederhana terdiri dari bagian yang membujur dan melintang, bagian yang membujur umumnya untuk mengikat bagian yang melintang agar kontruksi dari rangka tersebut kokoh dan kuat untuk menahan beban.

\section{Metode Penelitian}

Proses desain dalam proses pembuatan desain rangka hal pertama yang harus dilakukan ialah menentukan sudut pandang atau angel dalam inventor yaitu Start skect $2 D$ lalu menggunakan line untuk membuat pola pada rancangan frame. Adapun beberapa hal dalam membuat pola yang sulit menggunakan plane and geometry yang berfungsi untuk membuat pola pada bagian yang berlawanan dengan plane sebelumnya.

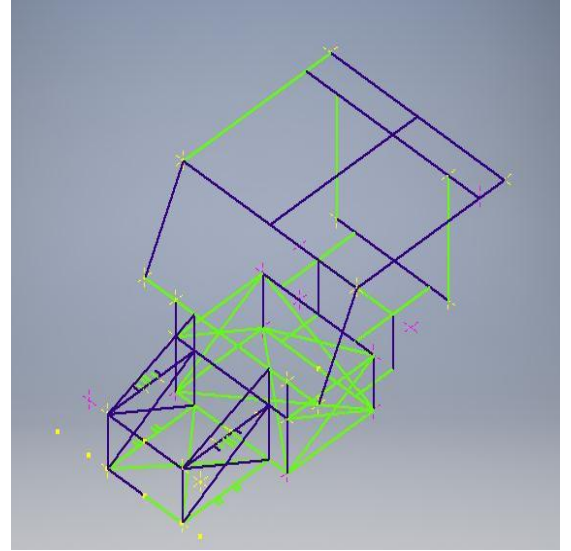

Gambar 2. Desain frame 2D

Proses selanjutnya setelah membuat desain 2D yaitu proses membuat 3D. Pada proses ini desain 2D di-save terlebih dahulu lalu membuka pada Tab My home pilih new skecth dan pilih assembly standard.

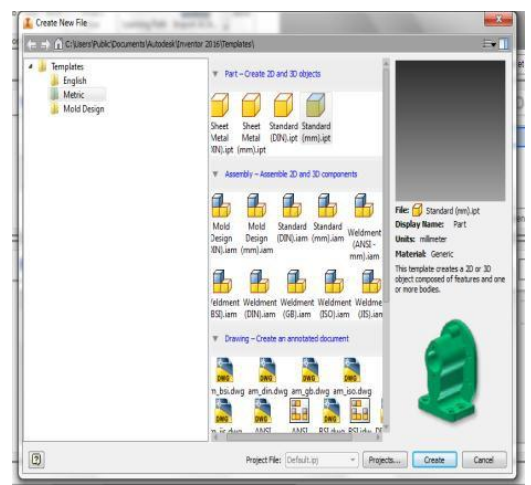

Gambar 3. Menu New Skect

Lalu masuk dalam design dan memilih insert frame pada insert frame terdapat menu material yang akan digunakan seperti pipa, persegi 4 dan lainlain.

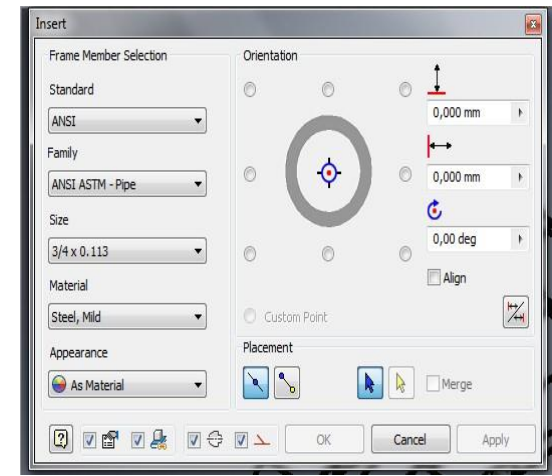

Gambar 4. Insert Frame

Setelah masuk ketahap pemilihan material dan bahan material yang akan digunakan masuklah pada proses 3D dengan 
cara meblock atau mengklik satu persatu desain 2D yang akan dirubah kedalam 3D.

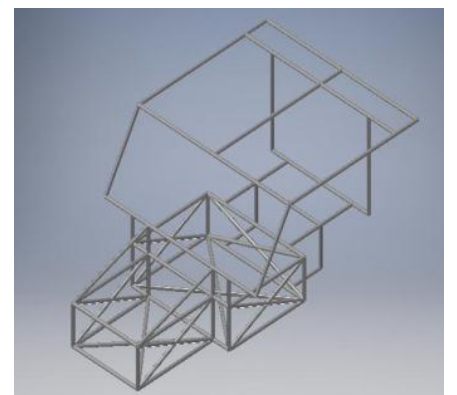

Gambar 5. Desain frame 3D

Proses simulasi yaitu dengan memberi fixed dan beban, setalah itu akan diketahui fenomena yang terjadi pada frame yang akan digunakan nantinya yaitu displacement, tegangan maximal dan minimal. Pada proses ini tidaklah sulit hanya dengan meng-klik simulate pada menu frame analysis maka dengan otomatis simulsi akan memproses data-data yang sudah dimasukan.

\section{Hasil dan Pembahasan}

Pada penelitian kali ini dalam perancangan rangka mobil listrik memliki dimensi yaitu panjang keseluruham rangka mobil $2200 \mathrm{~mm}$, lebar rangka total 1400 $\mathrm{mm}$, tinggi rangka pada bagian depan 300 $\mathrm{mm}$, dan tinggi rangka pada bagian belakang yaitu $1300 \mathrm{~mm}$ Pada hasil perhitungan analisis pembebanan beban yang bertumpu pada rangka depan yaitu $83,385 \mathrm{~N}$, pada bagian rangka tengah yaitu $1662,7 \mathrm{~N}$, dan pada bagian rangka belakang beban yang bertumpu sebesar 510,12 N. Pada perhitungan gaya yang dialami roda belakang pada titik C yaitu $3007 \mathrm{~N}$, dan pada gaya yang dialami roda bagian depan pada titik A sebesar $1504 \mathrm{~N}$, untuk hasil pengujian displacement dengan beban 230 $\mathrm{kg}$ diketahui displacement yang terjadi sebesar 0,6677 mm.

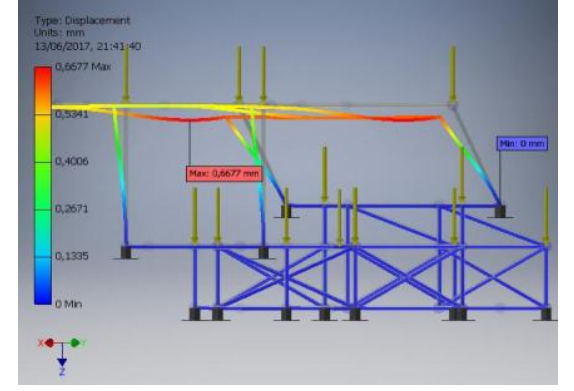

Gambar 6. Displacement Yang Terjadi Pada Rangka (Beban 230 kg)

Hasil pengujian stress diketahui tegangan maximal yang terjadi pada beban $230 \mathrm{~kg}$ 23,28 MPa pada gambar 7.

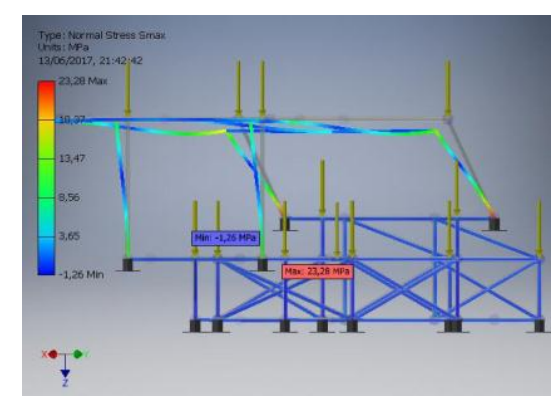

Gambar 7. Tegangan Maximal Yang

Terjadi Pada Rangka (Beban $230 \mathrm{~kg}$ )

Selanjutnya pada gambar 8 tegangan minimal yang terjadi sebesar 0,04 MPa.

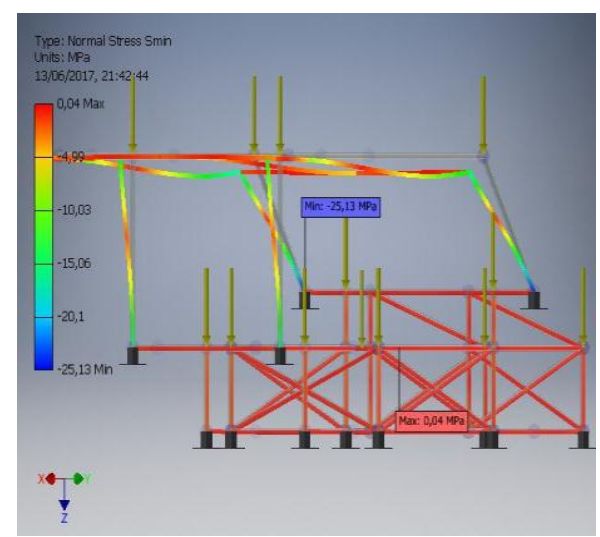

Gambar 8. Tegangan Minimal Yang terjadi pada rangka (beban 230)

Hasil dari proses pembebanan pada $280 \mathrm{~kg}$ displacement yang terjadi 0,7243 $\mathrm{mm}$. 


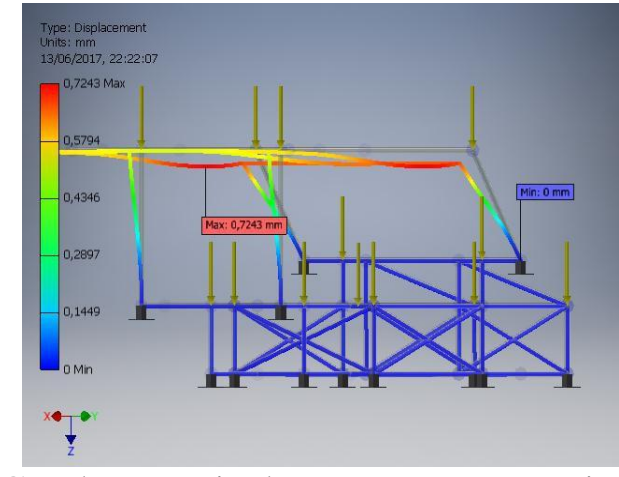

Gambar 9. Displacement Yang Terjadi

Pada Rangka (Beban 280 kg)

Pada pengujian dengan beban 280 $\mathrm{kg}$ tegangan maximal yang terjadi sebesar 25,2 Mpa, tegangan minimal yang terjadi yaitu $0,05 \mathrm{MPa}$.

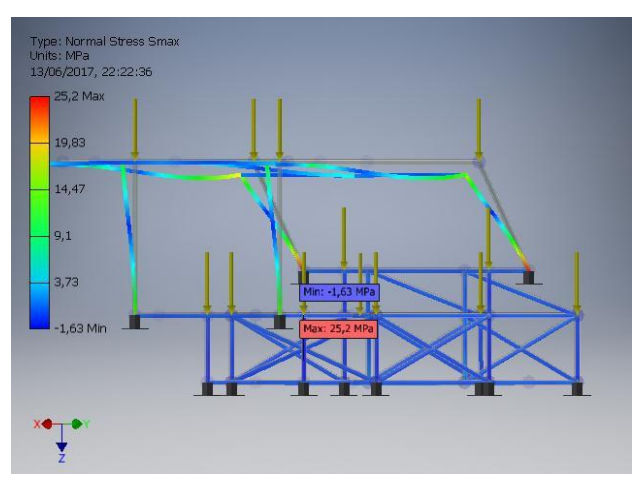

Gambar 10. Tegangan Maximal Yang Terjadi Pada Rangka (Beban $280 \mathrm{~kg}$ )

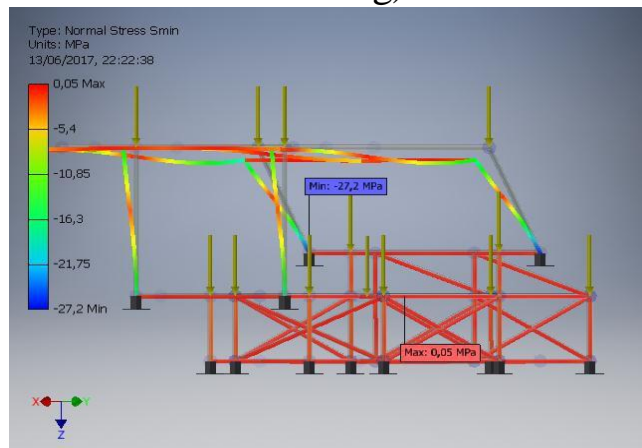

Gambar 11. Tegangan Minimal Yang Terjadi Pada Rangka (Beban 280 kg)

Untuk pengujian dengan beban $330 \mathrm{~kg}$ displacement yang terjadi sebesar 0,7809 mm. Pada pengujian dengan beban $330 \mathrm{~kg}$ diketahui tegangan dialami sebesar $27,12 \mathrm{MPa}$ dan tegangan minimal yang terjadi sebesar 0,06 MPa.

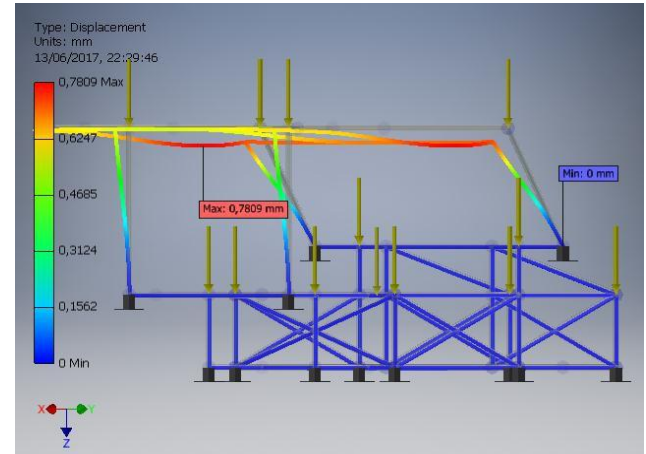

Gambar 12. Displacement Yang Terjadi Pada Rangka (Beban 330 kg)

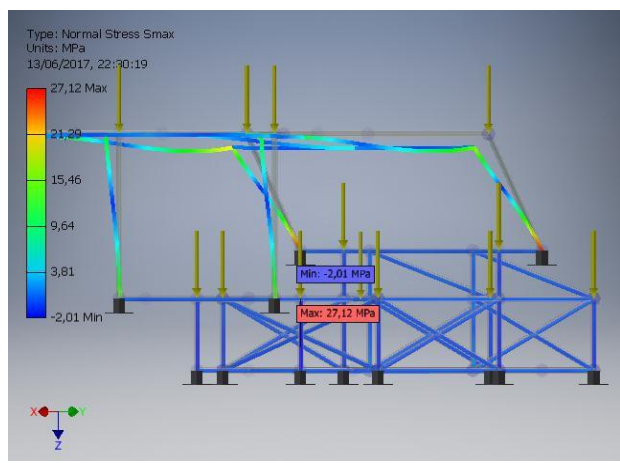

Gambar 13. Tegangan Maximal Yang Terjadi Pada Rangka (Beban $330 \mathrm{~kg}$ )

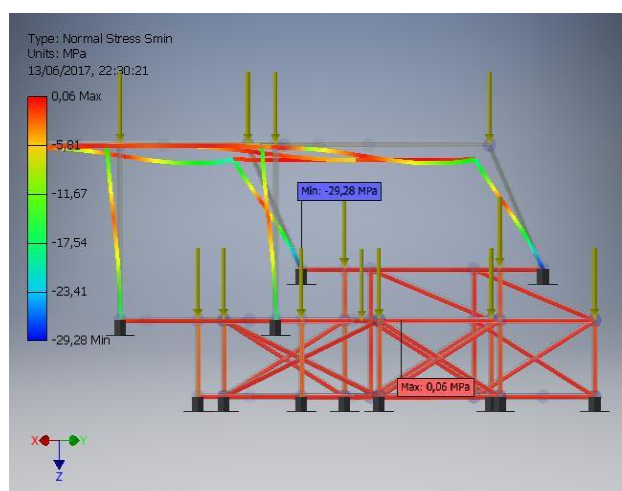

Gambar 14. Tegangan Minimal Yang Terjadi Pada Rangka (Beban 330 kg)

Pada hasil perhitungan analisis pembebanan beban yang bertumpu pada rangka depan yaitu 83,385 $\mathrm{N}$, pada bagian rangka tengah yaitu $1662,7 \mathrm{~N}$, dan pada bagian rangka belakang beban yang bertumpu sebesar 510,12 N. Pada perhitungan gaya yang dialami roda belakang pada titik C yaitu $3007 \mathrm{~N}$, dan pada gaya yang dialami roda bagian depan pada titik A sebesar $1504 \mathrm{~N}$, untuk hasil 
pengujian displacement dengan beban 230 $\mathrm{kg}$ diketahui displacement yang terjadi sebesar 0,6677 mm, pada beban $280 \mathrm{~kg}$ displacement yang terjadi $0,7243 \mathrm{~mm}$, dan untuk pengujian dengan beban $330 \mathrm{~kg}$ displacement yang terjadi sebesar 0,7809 $\mathrm{mm}$.

Hasil pengujian stress diketahui tegangan maximal yang terjadi pada beban

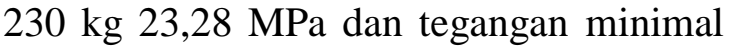
sebesar 0,04 $\mathrm{MPa}$, pada pengujian dengan beban $280 \mathrm{~kg}$ tegangan maximal yang terjadi sebesar 25,2 MPa, tegangan minimal yang terjadi yaitu $0,05 \mathrm{MPa}$, dan pada pengujian dengan beban $330 \mathrm{~kg}$ diketahui tegangan dialami sebesar 27,12 $\mathrm{MPa}$, dan tegangan minimal yang terjadi sebesar 0,06 MPa.Pada hasil safety factor dengan beban $230 \mathrm{~kg}$ didapat nilai faktor keamanan sebesar 10,3, pada pengujian dengan beban $280 \mathrm{~kg}$ didapat faktor keamanan dengan nilai sebesar 9,5, dan pada faktor kemanan dengan beban $330 \mathrm{~kg}$ didapat faktor keamanan sebesar 8,8 pada hasil perhitungan safety factor di atas didapatkan hasil faktor keamanan dengan nilai lebih dari 1 yang artinya rangka ini aman saat akan digunakan nantinya. Rancangan dikatakan baik dan layak produksi apabila hasil pengujian pada safety factor sudah berwarna biru yaitu dengan nilai minimal 3 . Safety factor minimal 4 merupakan kebijakan yang diterapkan dalam dunia industri [6].

\section{Kesimpulan}

Berdasarkan hasil perancangan dan analisis pada rangka mobil listrik menggunakan software autodesk inventor 2016 maka dapat diambil kesimpulan bahwa perancangan rangka dan simulasi didapat hasil yang berupa displacement pada beban $230 \mathrm{~kg}$ sebesar $0,6677 \mathrm{~mm}$, pada beban $280 \mathrm{~kg} 0,7243 \mathrm{~mm}$, dan pada beban $330 \mathrm{~kg}$ yaitu sebesar $0,7809 \mathrm{~mm}$.

Pada rangka diketahui tegangan maximal yang terjadi pada rangka dengan beban $230 \mathrm{~kg}$ sebesar 23,28 $\mathrm{MPa}$, sedangkan pada beban $280 \mathrm{~kg}$ tegangan yang terjadi sebesar 25,2 $\mathrm{MPa}$, dan pada beban $330 \mathrm{~kg}$ sebesar 27,12 MPa. Sedangkan pada tegangan minimal yang terjadi pada rangka dengan beban $230 \mathrm{~kg}$, $280 \mathrm{~kg}$, dan $330 \mathrm{~kg}$ sebesar 0,04 $\mathrm{MPa}$, 0,05 MPa, 0,06 MPa.

Pada perhitungan safety factor didapat angka keamanan dengan beban 230 $\mathrm{kg}$ sebesar 10,3 , pada beban $280 \mathrm{~kg}$ didapat angka keamanan sebesar 9,5, dan pada beban $330 \mathrm{~kg}$ didapat safety factor sebesar 8,8.

\section{Referensi}

[1] Setyono Bambang, dan Setyo Gunawan. Perancangan dan Analysis Mobil "Semut" Abang Menggunakan Software Autodesk Inventor 2013. Jurusan Teknik Mesin, Institut Teknologi Adhi Tama Surabaya ISBN 978-60298569-1-0.

[2] Kumara S Nyoman, dan I Wayan Sukerayasa. 2009. Tinjauan Perkembangan Kendaraan Listrik Dunia Hingga Sekarang Vol. 8 No.1 Januari - Juni.

[3] Syaifulah Arif Reza, Mobil Listrik "Zeon" (Zero Polution) Sebagai Sarana Wisata Di Ekowisata Mangrove Wonorejo.

[4] Fauzi Helmi. 2013. Analisa Tegangan Pada Frame Mobil Listrik sinosi Menggunakan Metode Elemen Hingga. Universitas Jember.

[5] Purwanto Heri Andi. 2015. Rancang Bangun Kendaraan EEC (Eelctric City Car). Politeknik Negeri Madiun.

[6] Sadikin Ali. 2013. Perancangan Rangka Chasis Mobil listrik Untuk 4 Penumpang Menggunakan Software 3D Siemens NX8. Universitas Negeri Semarang. 